\title{
STIMULATION RATIONALE
} FOR SHALE GAS WELLS

\section{A STATE-OF-THE-ART REPORT}

C. Young, T. Barbour, and T. L. Blanton

December 1980

Work Performed Under Contract No.: DE-AM21-78MC08216

For

U. S. Department of Energy

Office of Fossil Energy

Morgantown Energy Technology Center

Morgantown, West Virginia

By

Science Applications, Inc.

Steamboat Springs, Colorado

Technical Information Center

Office of Scientific and Technical Information

United States Department of Energy 


\section{DISCLAIMER}

This report was prepared as an account of work sponsored by an agency of the United States Government. Neither the United States Government nor any agency Thereof, nor any of their employees, makes any warranty, express or implied, or assumes any legal liability or responsibility for the accuracy, completeness, or usefulness of any information, apparatus, product, or process disclosed, or represents that its use would not infringe privately owned rights. Reference herein to any specific commercial product, process, or service by trade name, trademark, manufacturer, or otherwise does not necessarily constitute or imply its endorsement, recommendation, or favoring by the United States Government or any agency thereof. The views and opinions of authors expressed herein do not necessarily state or reflect those of the United States Government or any agency thereof. 


\section{DISCLAIMER}

Portions of this document may be illegible in electronic image products. Images are produced from the best available original document. 


\title{
DISCLAIMER
}

\begin{abstract}
This report was prepared as an account of work sponsored by an agency of the United States Government. Neither the United States Government nor any agency thereof, nor any of their employees, makes any warranty, express or implied, or assumes any legal liability or responsibility for the accuracy, completeness, or usefulness of any information, apparatus, product, or process disclosed, or represents that its use would not infringe privately owned rights. Reference herein to any specific commercial product, process, or service by trade name, trademark, manufacturer, or otherwise does not necessarily constitute or imply its endorsement, recommendation, or favoring by the United States Government or any agency thereof. The views and opinions of authors expressed herein do not necessarily state or reflect those of the United States Government or any agency thereof.
\end{abstract}

This report has been reproduced directly from the best available copy.

Available from the National Technical Information Service, U. S. Department of Commerce, Springfield, Virginia 22161.

Price: Printed Copy A03

Microfiche A01

Codes are used for pricing all publications. The code is determined by the number of pages in the publication. Information pertaining to the pricing codes can be found in the current issues of the following publications, which are generally available in most libraries: Energy Research Abstracts (ERA); Government Reports Announcements and Index (GRA and I); Scientific and Technical Abstract Reports (STAR); and publication NTIS-PR-360 available from NTIS at the above address. 


\title{
STIMULATION RATIONALE FOR SHALE GAS WELLS A STATE-OF-THE-ART REPORT
}

C. Young, T. Barbour, and T. L. Blanton

\section{December 1980}

Work Performed Under Contract No.: DE-AM21.78MC08216

\author{
For \\ U. S. Department of Energy \\ Office of Fossil Energy \\ Morgantown Energy Technology Center \\ P. O. Box 880 \\ Morgantown, West Virginia 26505
}

By

Science Applications, Inc.

P. O. Box 880010

Steamboat Springs, Coloradn 80488 
THIS PAGE

\section{WAS INTENTIONALLY LEFT BLANK}


Despite the large quantities of gas contained in the Devonian Shales, only a small percentage can be produced commercially by current production methods. This limited production derives both from the unique reservoir properties of the Devonian shales and the lack of stimulation technologies specifically designed for a shale reservoir.

Since October 1978 Science Applications, Inc. has been conducting a review and evaluation of various shale well stimulation techniques with the objective of defining a rationale for selecting certain treatments given certain reservoir conditions. Although this review and evaluation is ongoing and much more data will be required before a definitive rationale can be presented, the studies to date do allow for many preliminary observations and recommendations.

As shale well production is dominated by the in situ natural fracture system, it is imperative that significant efforts be made to quantitatively describe the in situ fracture system and its control upon shale well production. As the benefits of various explosive and hydraulic stimulation treatments clearly depend upon the interaction between the induced wellbore fractures and the pre-existing natural fractures, it is equally imperative that increased efforts be devoted to quantitatively understanding the effects of the stimulation treatments. Only by fully integrating fractured reservoir production characteristics with the effects of explosive and hydraulic treatments can a quantitative and supportable stimulation rationale be developed.

For the hydraulic type treatments the use of low-residual-fluid treatments is highly recommended. The lower the initial formation or reservoir pressure, the greater the benefit to be gained from low-residualfluid treatments. The excellent shale well production which is frequently observed with only moderate wellbore enlargement treatments indicates that attempts to extend fractures to greater distances with massive hydraulic treatments are not warranted. Immediate research efforts should be concentrated upon limiting production damage by fracturing fluids retained in the formation, and upon improving proppant transport and placement so as to maximize fracture conductivity. 
The occasionally spectacular production increases resulting from both conventional and displaced explosive treatments indicate that the modest wellbore enlargements resulting from such treatments may provide a viable and cost effective approach to shale well stimulation. Some, if not all, of the benefits obtained with displaced explosive treatments may be attributed to simple wellbore fracturing caused by the explosively generated gases acting in the wellbore. Recent laboratory and field results indicate that generation of these wellbore fractures is enhanced by reflection of the explosive gases off of the stem or tamp used to contain the shot. Continuing operational problems with displaced explosive systems further reduces the attractiveness of additional development efforts on this technique.

Recent laboratory, numerical modeling and field studies all indicate that the gas fracturing effects of explosive/propellant type treatments are the predominate production enhancement mechanism and that these effects can be controlled and optimized with properly designed charges. Future research efforts should be focused upon the understanding, prediction and control of wellbore fracturing with tailored-pulse-loading charges. These efforts must include fracture pressurization effects, the influences of natural fractures upon fracture propagation, mechanical and chemical formation damage effects, and the development of commercially acceptable hardware and fielding procedures. 
TABLE OF CONTENTS

PAGE

INTRODUCTION

DEVONIAN SHALE PRODUCTION CHARACTERISTICS 3

HYDRAULIC STIMULATION TREATMENTS

Conventional Hydraulic Treatments $\quad 6$

Massive Hydraulic Treatments $\quad 7$

$\begin{array}{ll}\text { Low-Residual-Fluid Treatments } & 7\end{array}$

EXPLOSIVE STIMULATION TREATMENTS 11

Conventional Explosive Stimulation $\quad 11$

Displaced Explosive Stimulation Techniques $\quad 21$

Tailored-Pulse-Loading $\quad 22$

CONCLUSIONS AND RECOMMENDATIONS 33

REFERENCES 36 


\section{INTRODUCTION}

The Devonian shales underlying large portions of the eastern United States contain an enormous quantity of natural gas with recent estimates ranging around $10^{15}$ cubic feet. At present only a small percentage of this gas is being recovered with annual production at a fraction of one trillion cubic feet per year and economically recoverable reserves estimated at 20 to 100 trillion cubic feet. The large disparity between annual production and estimated gas in place derives in part from the unconventional nature of this reservoir rock and in part from the lack of suitable technologies for economically recovering the gas. The unconventional reservoir conditions include in situ porosities and permeabilities that are largely controlled by natural fracture systems, the production of gas by desorption from organic rich sections of the shale, and low reservoir pressures which hinder clean-up after hydraul ic stimulation and limit production potential. The technologies which are currently utilized for stimulating and completing shale wells are either very old, empirically developed methods (such as well shooting), or the extension of techniques developed for conventional reservoirs and applied to shale wells on a trial and error basis (such as massive hydraulic fracturing). The development of improved completion and production techniques for Devonian shale wells will require significant research and development efforts on both shale production characteristics and the production modifications effected by conventional and novel stimulation treatments. The ultimate success of these research and development efforts will depend critically upon their integration with each other and with acceptable field practices.

In March 1978 Science Applications, Inc. (SAI) initiated an indepth review of Devonian shale production practices and the research efforts being undertaken to improve them (Young, 1978). This review included a two-day workshop held in Morgantown on May 18-19, 1978. This workshop concluded that Devonian shale production characteristics were unique and poorly understood and that the effects of stimulation treatments in such a unique reservoir were largely unknown. Accordingly the workshop made recommendations that research efforts in these two key areas be increased. Since October 1978, SAI has received several task orders (on an FGSP support contract, DE-AM21-78MC02816) from METC to inftiate the 
development of a stimulation rationale for Devonian shale wells. Efforts on these tasks have been largely restricted to: the collection of data on the effects of various stimulation treatments; the organization of, or attendance at, various technical meetings to discuss shale well stimulation technologies; the development and verification of numerical models to simulate the fracturing of explosive and propellant treatments; and the evaluation of the effects of various stimulation treatments upon reservoirs of differing production characteristics. The principal observations and conclusions derieved from these tasks are discussed in detail in the following sections. 
The lack of sophisticated, well-developed technologies for the completion, stimulation and production of Devonian shale wells is largely attributable to the unique production characteristics of this rock. The limited production potential of shale wells as controlled by erratic and unpredictable in situ fracture systems and typically low reservoir pressures have not provided a strong economic motive for developing improved recovery methods. The unconventional nature of Devonian shale reservoirs has made the prediction of production enhancement by the application of various conventional practices difficult, thus discouraging efforts to refine these practices for application to shale wells. While a detailed consideration of Devonian shale production characteristics was not included in the efforts undertaken in the stimulation technology development tasks reported upon here, the unique production characteristics of Devonian shale must be considered in developing a stimulation rationale; and therefore, the current understanding of shale production characteristics are summarized here. SAI is conducting separate task efforts, including reservoir simulations, and well testing to better define shale production characteristics.

There are two aspects of shale production behavior which serve to classify the rock as an unconventional reservoir. First, in situ permeabilities are most certainly controlled by natural fracture systems which may be highly heterogeneous and anisotropic and whose aerial and stratigraphic extent and interconnectedness are generally unknown. Second, laboratory data on recovered core material indicate that a large fraction of the gas in place may exist in chemically and physically sorbed states rather than as free gas in the rock. A better understanding of the role that the natural fracture systems play in controlling shale production is critical to the development of improved stimulation technologies and the rationale for their application. The role of gas desorption is critical to the long-term production of shale wells; but is less important to the development of stimulation technologies and the economics of early production where the production is controlled predominantly by free gas in the natural fracture system.

The unconventional nature of Devonian shale reservoirs and the role that natural fracture system permeability contributes to this 
behavior are well demostrated by shale well drilling, stimulation, and completion statistics. Forty percent of all shale wells drilled have had no measurable gas flow during initial open hole testing and fifty-five percent have had sub-commercial initial open flows, (Smith, et al., 1979). Only five percent of as drilled wells have had commercial open flows. Stimulation of wells with no measurable and sub-commercial initial flows, usually by simple borehole shooting, has resulted in nearly $90 \%$ of such wells becoming commercial producers. Typically, open flows of over 50,000 cubic feet per day are required to provide a commercial wel1. As conventional borehole shooting can, at best, extend fractures on the order of ten feet from the wellbore, the dramatic increases in productivity when initially dry wells are shot can only be explained by fracture controlled permeability. The heterogeneity of this fracture permeability is such that a 6 to 8 inch wellbore can fail to intersect zones of high permeability and yet a wellbore enlargement of a few feet can provide satisfactory communication with the in situ fracture system. A better description of in situ fracture spacing would be quite valuable to the better understanding of explosive stimulation effects and to the optimization of explosive treatments.

The success of explnsive treatments requires that such treatments intersect production characteristics (e.g. fracture systems) which were not intersected by the initial well despite the limited wellbore enlargement that can be achiever by explosive means. In cunlrast, hydraulic fracture treatments can provide theoretically effective wellbore radii of several hundred feet, but the modest increases in production as compared to explosive treatments imply that the effective fracture length is much less than the predicted fracture length. The stimulation response of wells with measurable but marginally commercidl initlal open flows also dictates a heterogeneous production characteristic most likely controlled by the natural fracture system. Only 5\% of Devunian shale wells have had initial flows so large that no stimulation treatment was required. The unique feature of these very high initial productivity wells is that they occur interspersed with wells with marginal or no measurable initial production rather than occurring clustered in areas that might be associated with a high productivity reservoir. That one well in 20 will intersect in situ characteristics providing high production 
while its nearest neighbors fail to do so further attests to the largescale heterogeneity of shale permeabilities as controlled by natural fracture systems.

An effective stimulation rationale for Devonian shale wells must have available to it stimulation techniques capable of effectively communicating with in situ fracture systems, modeling methods for predicting the production effects of intersecting natural with induced fracture systems and, finally, statistical, geological, and geophysical exploration means for predicting in situ fracture densities. 
HYDRAULIC STIMULATION TREATMENTS

Until the early 1970's the artificially low prices for natural gas and the consequent marginal economics of Devonian shale production dictated that only conventional explosive stimulation techniques be utilized to improve shale production. With increasing gas prices and economic potential, the more expensive hydraulic treatiments began to be considered, tested and evaluated. Initially only conventional water or water/gel treatments with sand as a propping agent were considered. With the inception of the Eastern Gas Shales Project, interest in possibly increasing shale well production even further with massive hydraulic treatments or the use of special fracturing fluids was developed. In general these specialized fluids may be categorized as low residual fluid or energy assisted fluids, such as a nitrogen foam or a cryogenic fluid. The data on enhanced production by conventional hydraulic treatments, massive-hydraulic treatments and low-residual fluid treaments are adequate for drawing some general conclusions on the relative success of these treatments and the rationale for their selection.

\section{Conventional Hydraulic Treatments}

In shale well stimulation, conventional hydraulfc treaments are characterized as those involving less than 100,000 gallons of water or gelled water as the fracturing fluid. An extensive evaluation of conventional hydraulic treaments was done in comparison with explosive treatments by Yost (1978). In this study, the production decline curves for up to 5 years for comparable explosively and hydraulically stimulated wells were analyzed. While the data presented by Yost indicate that conventional hydraulic treatments would be preferred for shale wells in southern West Virginia and eastern Kentucky, data do not exist to extrapolate this observation to other areas of shale production. Given the significantly higher costs for completing a shale well with a hydraulic stimulation treatment as compared to an explosive treatment, the economic benefits of one treatment compared to the other cannot be fully evaluated at this time. Devonian shale producers are currently employing both conventional explosives and conventional hydraulic treatments in the completion of their wells. In general, their rationale is based upon a 
continuation of a technique which has proven economically viable in the region and under the conditions in which they are operating.

Massive Hydraulic Treatments

The testing and evaluation of large-scale, massive hydraulic stimulation treatments has been limited to a 3 well program conducted jointly by Columbia Gas Corporation and the Department of Energy (Cremean, et al., 1979). Although the three wells in this program were planned for true massive hydraulic treatment, severe clean-up problems with the first zone treated in well 20401, as indicated in Table 1, resulted in all subsequent treatments being either foam or modified foam types. The results of the Columbia/DOE three well program illustrate that severe clean-up problems can be expected for large-scale treatments in a lowpressure shale reservoir. The clean-up difficulties with these wells, even when a modified foam was used, suggest that fluid retention in even small-scale hydraulic treatments may provide important limitations on production. The large-scale treatments utilizing a nitrogen foam as an energy assist fluid suggest that while the clean-up problem may be significantly reduced with such a fluid, production enhancement warranting the increased cost of such treatments does not occur. Unless it can be demonstreated that the effective length of the fractures developed by large-scale, low residual fluid treatments is sufficiently large and that shale production characteristics would be responsive to such fractures, the economic application of large-scale or massive hydraulic treatments will not be attractive for shale well production.

Low-Residual-Fluid Treatments

The clean-up problems associated with both conventional and massive hydraulic treatments in the lower pressure shale reservotrs have caused serious consideration to be given to energy assisted fluids as fracturing media. These treatments utilize a gas drive provided by nitrogen $\left(\mathrm{N}_{2}\right)$ or carbon dioxide $\left(\mathrm{CO}_{2}\right)$ to aid in producing back the fracturing fluid after the treatment. Also, because relatively little or no water is used there is less water damage to the formation. The three types of treatments that have.been tried in Devonian shajes are cryogenic treatments utilizing liquid $\mathrm{CO}_{2}$ and water, foam treatments 
TABLE 1 - TREATMENT PARAMETERS

FOR

MASSIVE HYDRAULIC FRACTURING TESTS

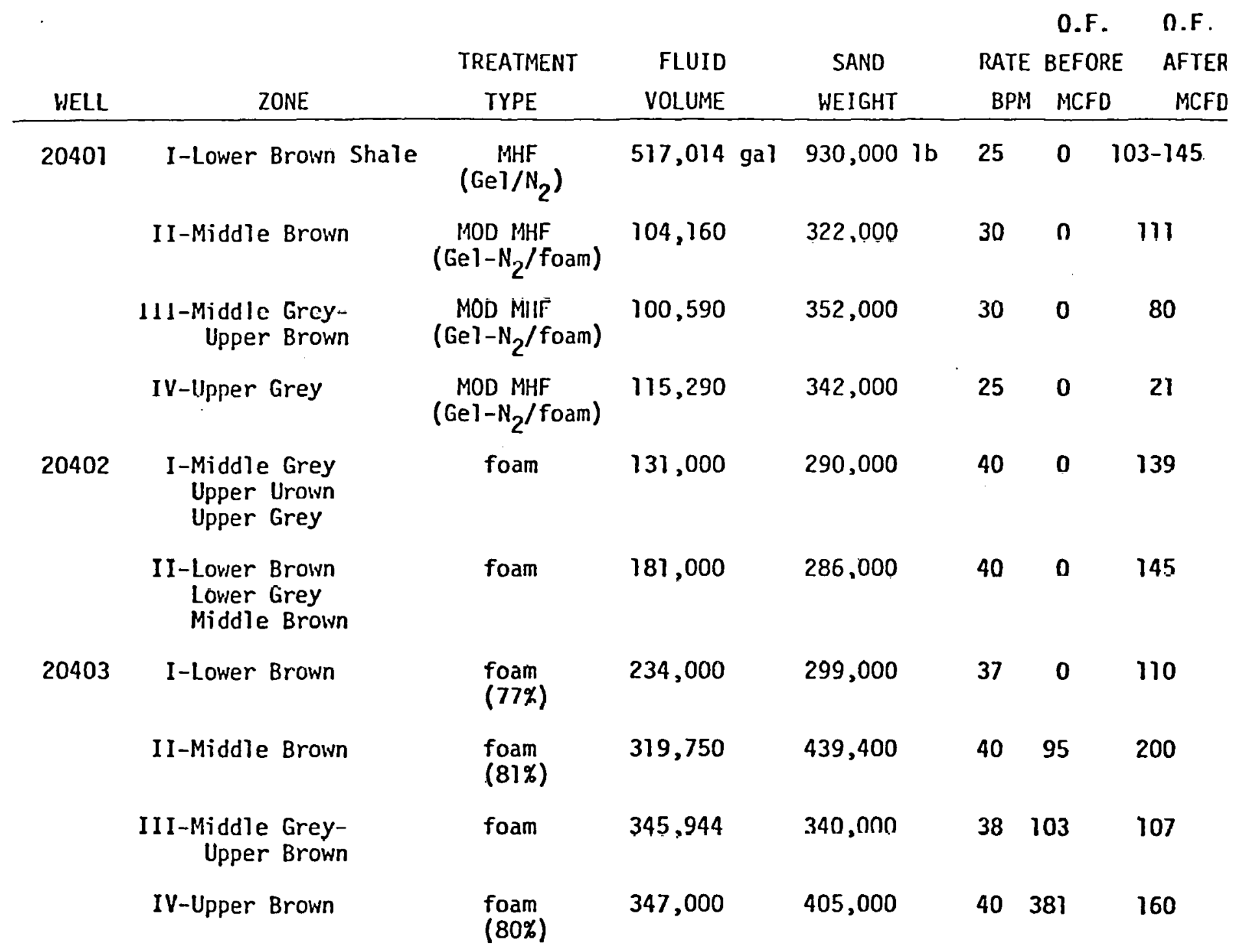


utilizing $\mathrm{N}_{2}$ and water with a foaming agent, and straight $\mathrm{N}_{2}$ treatments.

Only a minimal number of cryogenic treatments have been

attempted in shale wells. On a joint industry/DOE program, Columbia Gas treated two intervals in each of three wells with fluid volumes ranging from 43,560 gal to $139,760 \mathrm{gal}$. All zones treated had no measurable prestimulation. flow, and the most successfully stimulated zone gave a 370 Mcf per day initial open flow after stimulation. While these cryogenic treatments gave an excellent clean-up and post stimulation production, the high cost of the treatments dictates that they be applied to higher temperature $\left(>150^{\circ} \mathrm{F}\right)$ and higher in situ stress (treatment pressure) reservoirs where foam treatments would be inoperative.

Using $\mathrm{N}_{2}$ to create a foam in fracturing fluids was introduced in the oil and gas industry approximately six years ago (Blaurer, 1975). The main advantage in using foam is the energy-assist to clean-up provided by the gaseous phase. Fast, efficient clean-up minimizes formation damage due to the short contact time with the fluid and allows the well to be tested and put on production much sooner. Other advantages are high volume efficiency due to low fluid leak-off, good sand transport due to high viscosity in the fracture, and low friction loss in the pipe.

Several factors that limit the use of foam in other areas are not a problem in the Devonian gas shales. Use of foam is 1 imited to temperatures below $150^{\circ} \mathrm{F}$ and treating pressures below 3000 psi. Because the Devonian shale is a relatively low temperature, low pressure reservoir, these are not serious restrictions. Another problem with foam is that gas leak-off can be high, but because the Devonian shale has a very low matrix permeability, leak-off is not a severe problem.

Limitations in the use of foam fracturing in Devonian shales have to do with sand concentration and cost effectiveness. Because sand is added to the liquid phase before introduction of the foaming agent, sand concentrations are low. Propparits have been found to be necessary for sustained production in the Devonian shales. Whether or not the increased cost of foam treatments is justified by increased production will probably depend on the ability to identify reservoirs with sufficient capacity to be exploited by hydraulic fracturing (Komar, et al., 1979; Liebenthal, et al., 1979). 
Straight $\mathrm{N}_{2}$ has been used as a fracturing medium with increasing frequency over the last two years. The main advantage of an $\mathrm{N}_{2}$ treatment is the simplicity of running the job since only a single phase is involved. The main disadvantage is the inability to transport proppant into the fracture. Another disadvantage is that the fluid cannot be diverted with perf balls; however, at least one service company ( $\mathrm{B}-\mathrm{J}$ Hughes) is working on a ball injector to use with $\mathrm{N}_{2}$ treatments.

The size of $\mathrm{N}_{2}$ treatments ranges from 50,000 standard cubic feet (scf), which is the amount contained in one truck, to 1,000,000 scf. Field engineers for two service companies independently estimated the average job to be 200,000 scf. Ordinarily high leak-off rates would be expected with the uce of $\mathrm{N}_{2}$, making it an inefficient medium from the viewpoint of fracture length produced for a given volume of $\mathrm{N}_{2}$. Apparently this is not a problem in Devonian shales because of their low permeability. The fracture produced by a 9,680,000 scf treatment run in Knox County, Ohio, intersected a well $460 \mathrm{~m}$ (1500 ft) away (Evans, et a1., 1980). Fracture design calculations made for the offset Well Test Program suggest that a 50,000 scf job could produce a fracture about $30 \mathrm{~m}$ high and $30 \mathrm{~m} \mathrm{long}$, taking into account leak-off (Blanton, 1980). It appears that substantial fracture lengths can be obtained with relatively small volumes of $\mathrm{N}_{2}$ but because proppant is not used the desirability of long fractures is questionable. Without proppant there is an increased likplihond that most of the length of the fracture will be cut off from the wellbore when the fracture closes. An $\mathrm{N}_{2}$ treatment is probabiy most effeclive when used in situations where the main objective is to connect the wellbore to the natural fracture system. In this sense it should be considered as an alternative to wellborc shooting. Given the fracture lengths obtained in the well in Knox County, Ohio and in the design calculations for the offset Well Test Program, and considering that most of the natural fracture spacings are at most $3 \mathrm{~m}$, it may be possible to effectively stimulate more than one zone or well from a single $\mathrm{N}_{2}$ truck. 
The explosive stimulation of Devonian shale wells with $80 \%$ gel dynamite has been successfully utilized for more than thirty years. The economic success of such conventional explosive well stimulation is related to the small incremental cost of such treatments and the unique production characteristics of Devonian shale. While hydraulic stimulation treatments usually require that the well be cased, cemented, and perforated through the potentially productive section, an explosive treatment is conducted in an open hole, requires no special well preparation, and may be conducted with no surface equipment other than a wirel ine workover rig. The typical costs for explosive treatments range from one-quarter to one-half of those for a hydraulic treatment. When ultimate production is neither assured nor apt to be spectacular, the lower costs of explosive treatments are especially attractive to the independent operator. As discussed in the preceeding section on hydraulic stimulation treatments, the very large relative increases in production realized with explosive treatments and the consistent elevation of an economically non-productive well to a productive well explain the continued acceptance of conventional explosive stimulation and the interest in improved or novel explosive techniques.

Conventional Explosive Stimulation

Despite the economic, albeit marginal, success of conventional explosive treatments in Devonian shale wells, practically no efforts have been devoted to either understanding the physical benefits of such treatments or attempting to significantly improve the state-of-the-art. Consequently, conventional explosive stimulations are conducted much as they were thirty years ago. The rontinued success and acceptance of explosive stimulation treatments in shale wells, while such treatments have been completely replaced by hydraulic stimulation techniques in more conventional reservoirs, implies that Devonian shale production is controlled by features which are uniquely responsive to explosively induced fractures. The prevoiusly mentioned erratic and wideranging initial production behavior of shale wells provides some indication and measure of the unique shale production characteristics. The broad ranges in initial production can only be explained if shale well production is controlled predominantly by a coarsely spaced natural fracture system. Both the frequency of wells with an initial, nonstimulated, commercial production and 
the occurrences of vertical fractures in shale cores could be utilized to make a statistical estimate of the fracture spacing that controls production. Rough calculations indicate that the production controlling fractures must have spacing on the order of three meters (10 feet) and that such fractures are certainly very coarsely spaced compared to wellbore diameters. Thus, the drilled shale well has a low probability of intersecting significantly the production controlling fractures but a minimal enlargement of the effective wellbore radius, such as effected by conventional explosive stimulation, has an excellent probability of intersecting adequately the natural fracture system.

While conventional explosive stimulation treatments most certainiy generate wellbore fractures which provide an effective wellbore radius of a few meters, these treatments could cause signiricanl wellbore damage in terms of permanent non-elastic deformation of the rock around the woll bore and in terms of fracture-plugging fines. Efforts to understand the explosive stimulation process, with the goal to minimize wellbore damage and to maximize effective wellbore fractures, could yield significantly improved benefits for explosive-type stimulation treatments. The current practice of using four-inch diameter explosive charges in a six or seven-inch diameter open hole probably represents the empirical development of a technique for minimizing wellbore damage. If the wellbore were completely loaded with explosives, the peak stresses experienced by the rock in contact with the explosives would exceed by several orders of magnitude the compressive and crushing strengths of the rock. By slightly decoupling the explosive charge from the wellbore wall, the peak stresses applied to the rock are significantly reduced such that the majority of rock damage involves tensile fracturing caused by the explosively generated gases.

A computational evaluation using the STEALTH* (Hofmann, 1978) explicit finite difference codes in conjunction with the CAVS $^{\dagger}$ (Maxwe11, 1979) tensile

* STEALTH (Solids and Thermal Hydraulics code for EPRI adapted from Lagrange TOODY and HER:P) was developed by Science Applications, Inc., under EPRI Contract $\mathrm{R} \overline{\mathrm{P}}-307$ )

${ }^{\dagger}$ CAVS (Cracking and Void Strain) 
failure model has been performed (Barbour, et al., 1980 b) to assess the conventional decoupled dynamite treatment in stimulating gaseous shale. Results of the numerical simulation included descriptions of the wellbore expansion due to yielding, induced lenstle crack development and gas flow from the wellbore into induced fractures. The one-dimensional, cylindrical geometry model described the detonation of a four-inch diameter, $80 \%$ gel dynamite charge in a $7 \frac{3}{2}$ inch diameter open wellibore in a zone of browin gaseous shale at a depth of 3200 feet ( 975 meters). Computed results at the end of the dynamic phase of the stimulation (approximately 2 milliseconds after detonation) indicate that significant yielding will occur, permanently enlarging the wellbore to about $83 / 4$ inches in diameter (Figure $1 a$ ). This near wellbore yielding may cause significant wellbore damage precluding access to the treated zone and possibly interfering with wellbore to formation communication. The stress redistribution associated with the yielding, prohibits tensile failure near the borehole and thus, prohibits gas flow from the wellbore into the cracks beyond the plastic zone. In order to assess the influence of internal crack pressurization on the fracture development, the region of expected yielding was computationally pre-cracked to allow gas flow from the wellbore. The extent of multiple radial crack development in this instance is approximately 2.4 meters. Figures $1 b$ and $1 c$ show the radial fractures that are computed using the CAVS model at 1 millisecond and 2 milliseconds, respectively. Future computations simulating dynamite shots might consider a smaller diameter charge (say, 2 or 3 inches in diameter) to minimize the yielding, yet induce sufficient cracking. A two inch diameter charge with better gas generation or a three inch charge with a more optimal rise-time may provide the same fracture development without the yielding.

Research efforts could be effectively utilized to define the ideal explosive decoupling factor or the type of decoupling fluid for a given set of rock properties and natural fracture spacing, however it would also be beneficial to consider the development and application of explosives with maximum energy release, lower detonation pressures and greater gas generating characteristics. An explosive displaying these features, du Pont EL 836, has been developed and is currentiy being evaluated to assess its suitability for gas well stimulation. 


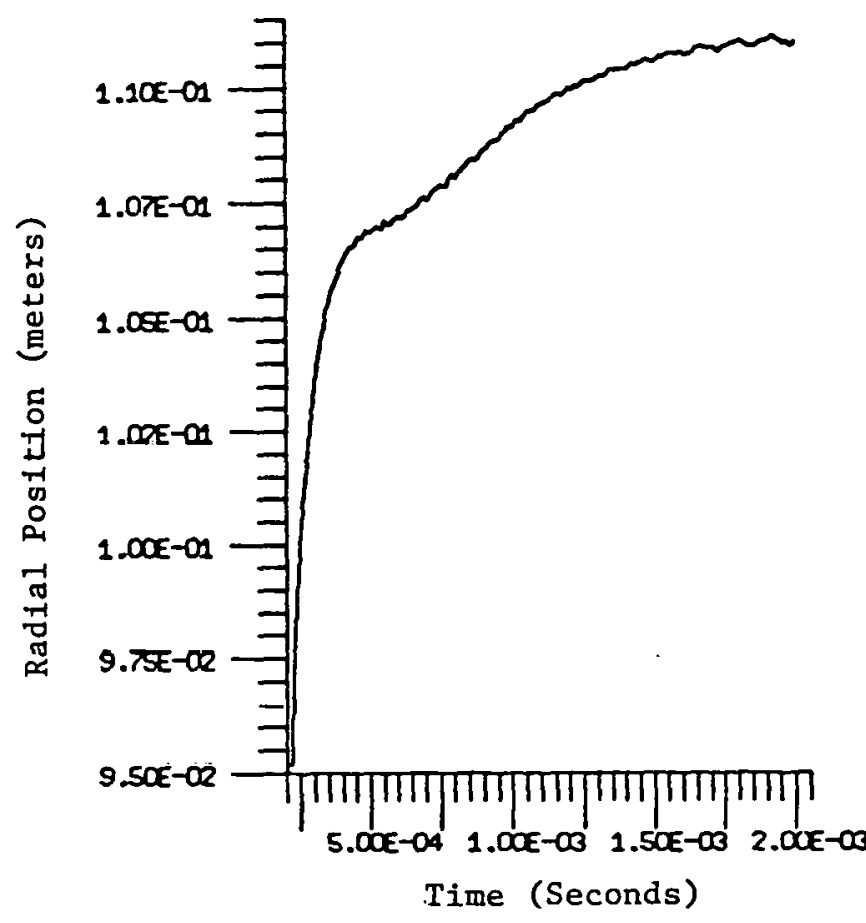

a) We11bore Expansion

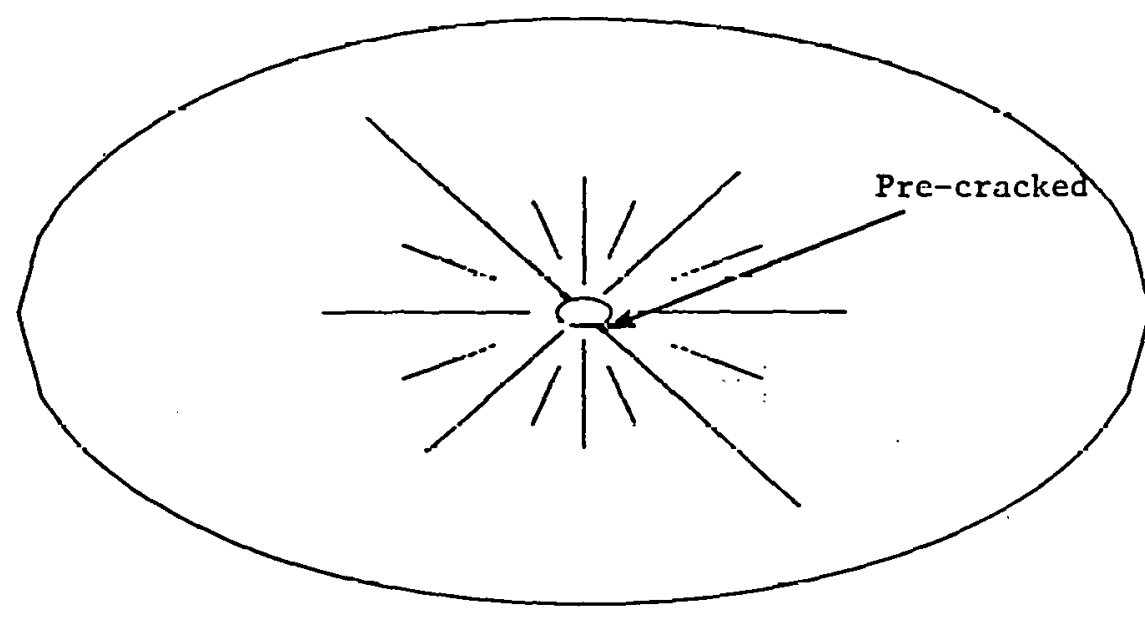

b) Radial Cracks at 1 Millisecond

(Borehole Radius $=0.13$ meters, Outside Boundary $=2.4$ meters)

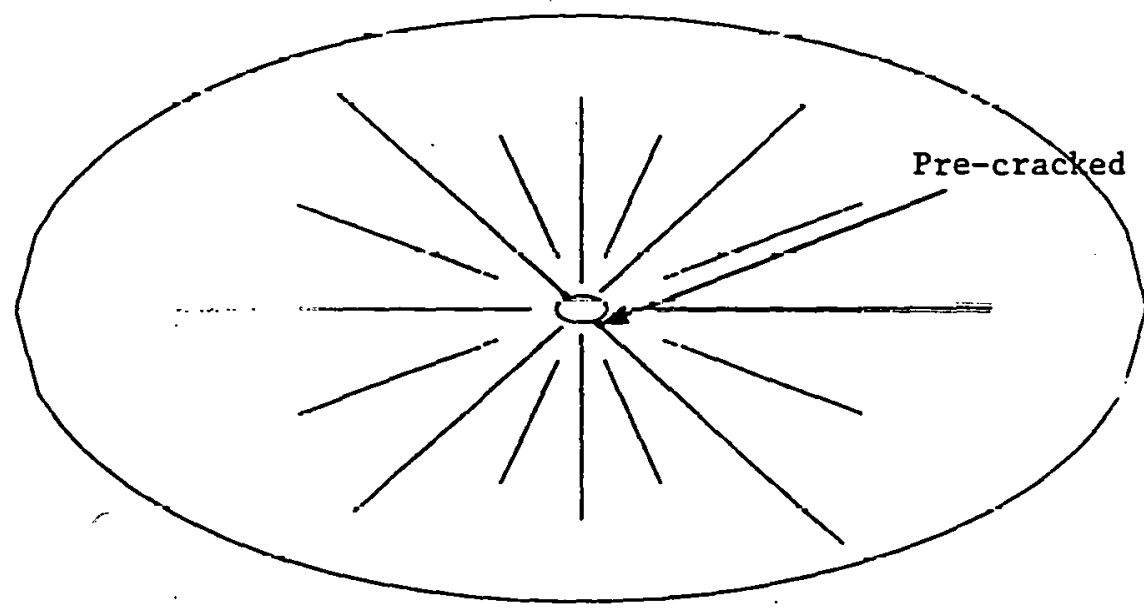

c) Radial Cracks at 2 Milliseconds, no duditional rrarking after 2 Milliseconds

(Borehule Radius $=0.13$ meters, Outside Boundary $=2.4$ meters)

FIGURE 1. Conventional Decoupled Dynamite Stimulation of Gas Shale 
Du Pont is currently engaged in a nine well test program, under contract to METC, to evaluate the EL836 explosive in stimulating shale gas wells and to compare initial open-flow and production data against conventional dynamite treatments (Lovings and Simmons, 1980). Charge lengths of 500 - 600 feet were used to stimulate shale zones at depths between 4000 - 5000 feet. Three wells were treated with 6000 pounds of cartridged $80 \%$ gel dynamite over an interval of 600 feet. These charges were 5 inches in diameter centralized in $6 \frac{1}{4}$ inch diameter wellbore. Five wells were treated with 12000 pound EL836 charges over an interval of 600 feet. These charges filled the $6 \frac{3}{4}$ inch wellbore. One EL836 test was performed in an under-reamed wellbore (reamed to 12 inches in diameter over a 500 foot interval). The total charge weight of this test was 37,500 pounds.

While initial open-flow data is encouraging for those wells treated with EL836, a complete evaluation of the success or improvement over conventional dynamite treatments cannot be established until the production data, gathered over the next three years, can be analyzed. Preliminary evaluation of the initial open-flow data substantiates the premise (Coursen, 1980) that the greater the energy release of an explosive stimulation treatment, the greater the effective radius of the shot wells. Analysis of the open flow data suggest that the open-flow rate is proportional to the effective fracture radius and that the effective radius is proportional to the square-root of the total energy released (Loving and Simmons, 1980).

Significant wellbore yielding is expected for most explosive stimulation treatments and is often thought to create an impermeable barrier to gas penetration into induced fractures during stimulation and to gas flow from the formation into the wellbore after stimulation. Improved open-flow data observed in the EL836 tests indicate, however, that even with significant inelastic deformation and increased residual compressive tangential stresses around the wellbore this region is likely to have a fracture permeability. resulting from near-wellbore shear deformation and crushing.

Results of a computational evaluation (Barbour, 1980) of the EL836 explosive in stimulating Devonian gas shale using the STEALTH/CAVS codes suggest the following: 
1) Significant plastic yielding will occur in a region immediate to the borehole. For typical gas shale, this region extends to about three borehole radii. Figure 2 shows the computed wellbore expansion.

2) Extensive tensile fracture will occur in a region that begins at the outer boundary of the near-wellbore plastic deformation region and terminates at more than 100 borchole radii (approximately 10 meters). Figure 3 shows the computed radial fractures at 1, 2, 3 and 4 milliseconds after explosive detonation.

3) Without a mechanism of near-wellbore fracture, such as crushing or pre-cracking during drilling, the plasllc flow that occurs adjacent to the wellhnre causes stress redistributions which prohibit early-time (less than a millisecond) tensile fracture immediate to the wellbore and thus prohibits gas penetration from the wellbore into the crack system.

4) The barrier that the near-wellbore plastic zone presents to gas flow from the wellbore is reduced in radial dimension as time increases. It would thus be expected that at late times in the EL836 stimulation treatment breakthrough would be achieved, enabling gas penetration into the crack system.

5) Natural fractures in the wellbore wall or cataclastic deformation and fracture adjacent to the wellbore, as a result of the explosive detonation, will likely assist in breaking down the barrier to gas flow, and thus enable early-time gas penetration.

6) Very significant enhancement is achieved in the EL836 stimulation treatment when gases penetrate the stress-wave induced radial cracks. Crack opening is increased by an order-of-magnitude and crack extension is improved. Figure 4 shows the effect of crack internal pressurization on the distribution of radial cracks and on the distribution of radial crack void strain. 


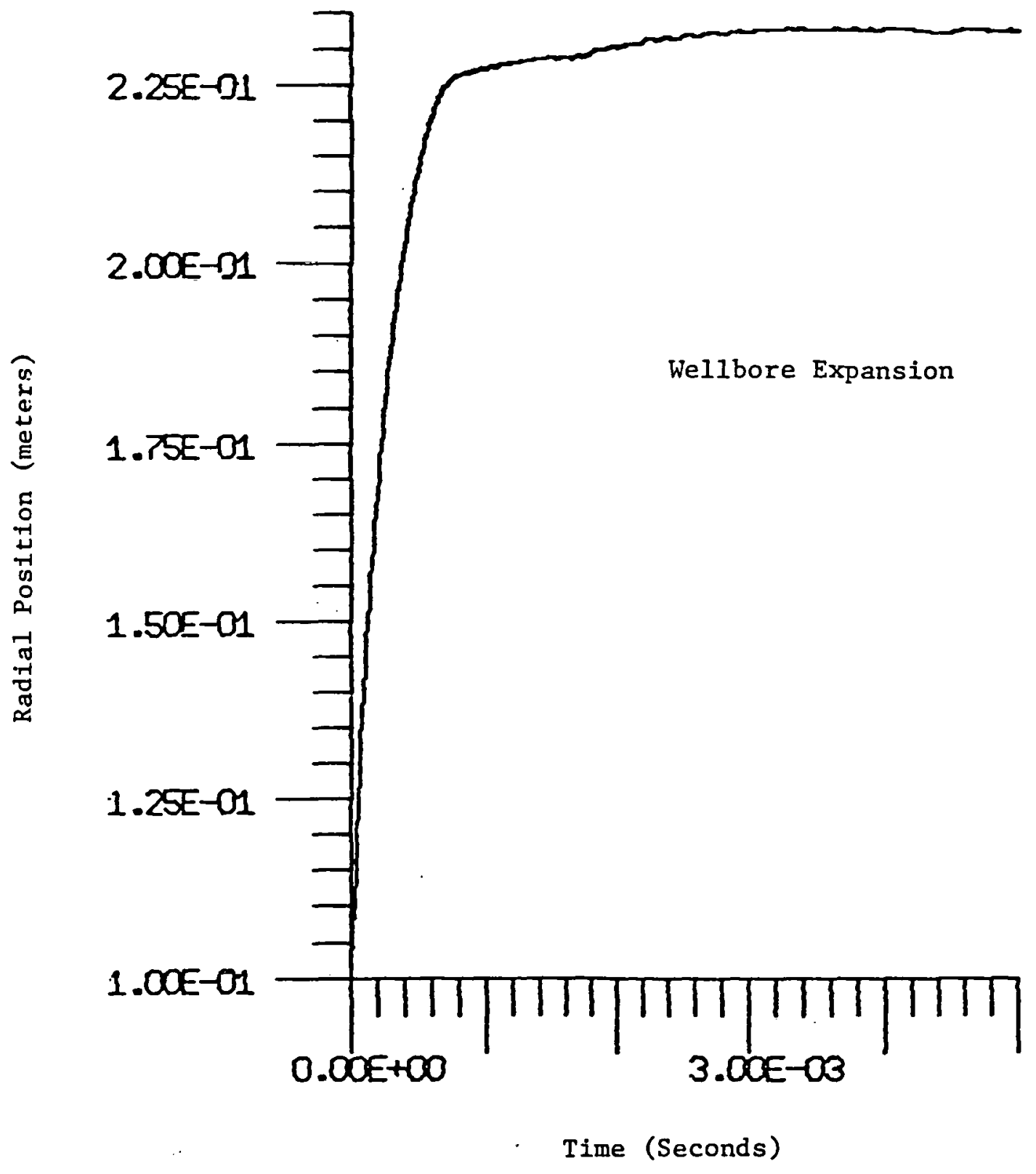

FIGURE 2. EL836 Stimulation of Gas Shale 


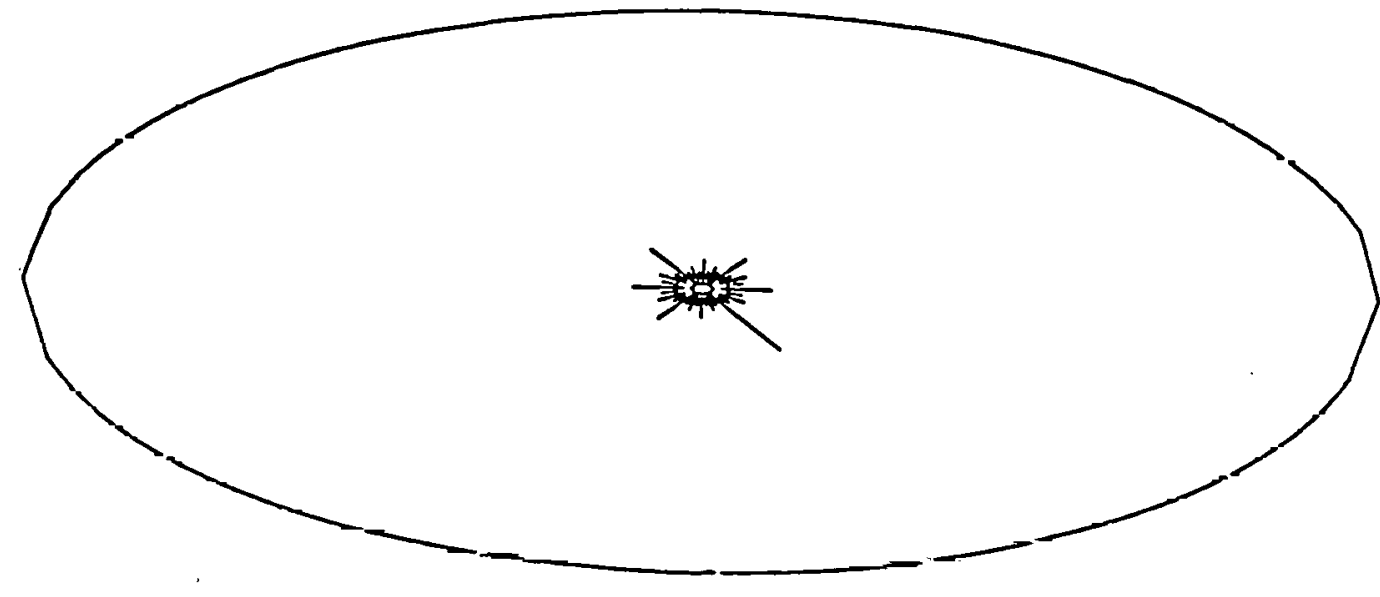

a) Radial Cracks at 1 Millisecond (Borehole Radius = 0.10 meters Outside Boundary = 14.0 inetêrs)

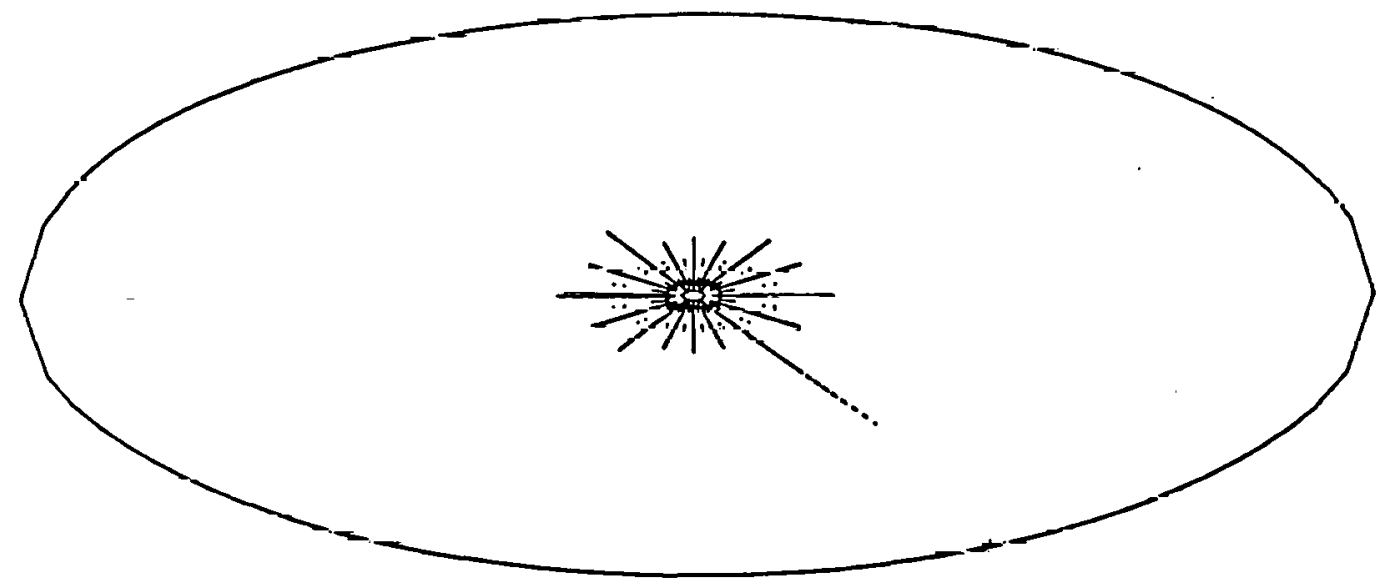

b) Radial Cracks at 2 Milliseconds

(Borehole Radius = 0.10 meters Outside Boundary = 14.0 meters)

FIGURE 3. EL836 Stimulation of Gas Shale 


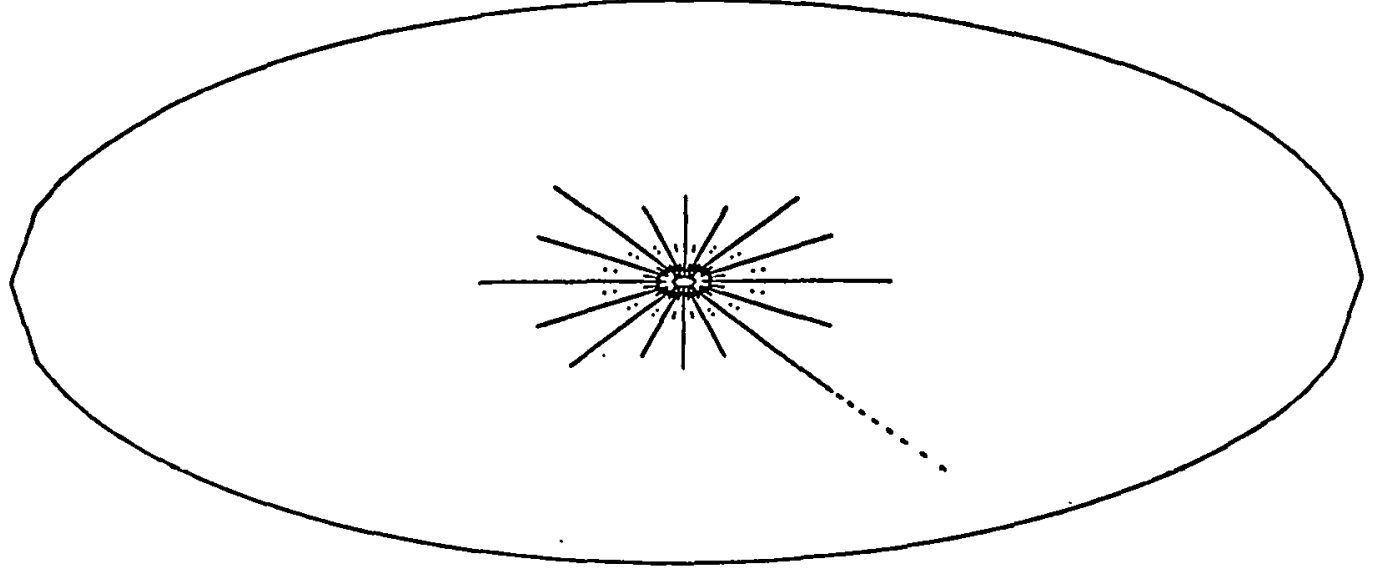

c) Radial Cracks at 3 Milliseconds

(Borehole Radius = 0.10 meters) Outside Boundary = 14.0 meters)

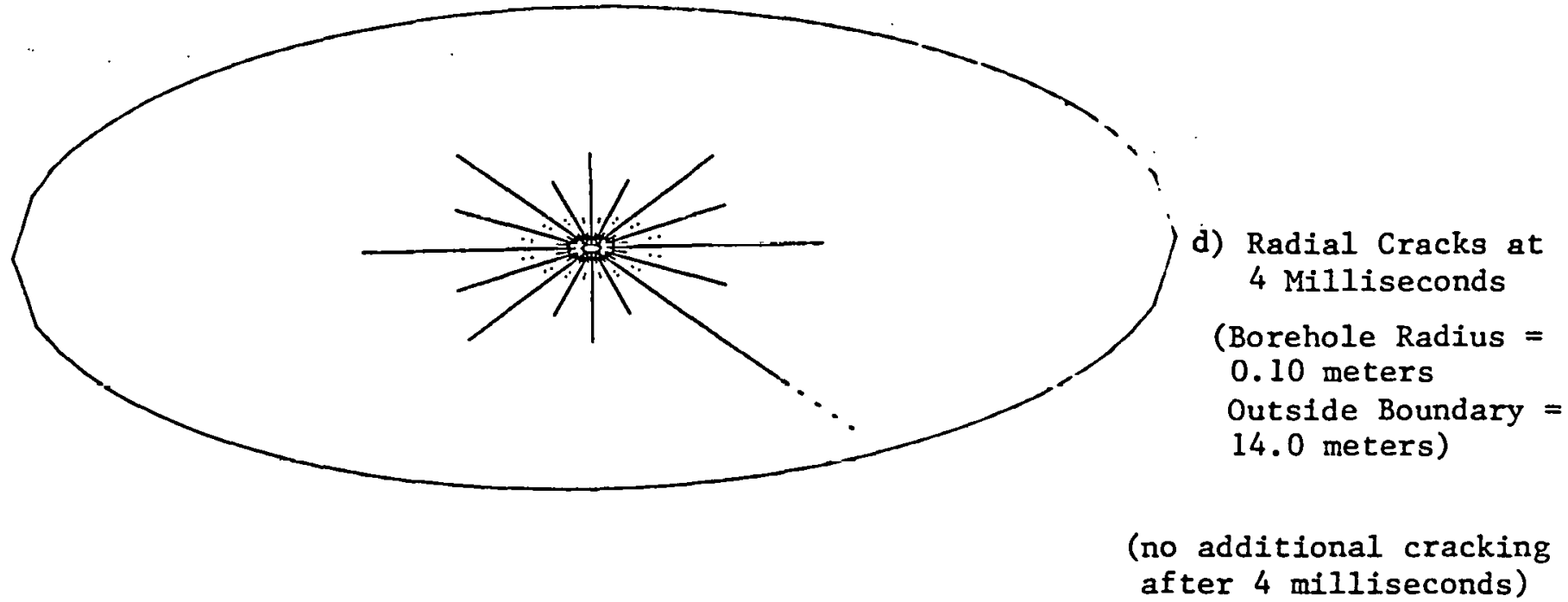

FIGURE 3 (Continued). EL836 Stimulation of Gas Shale 

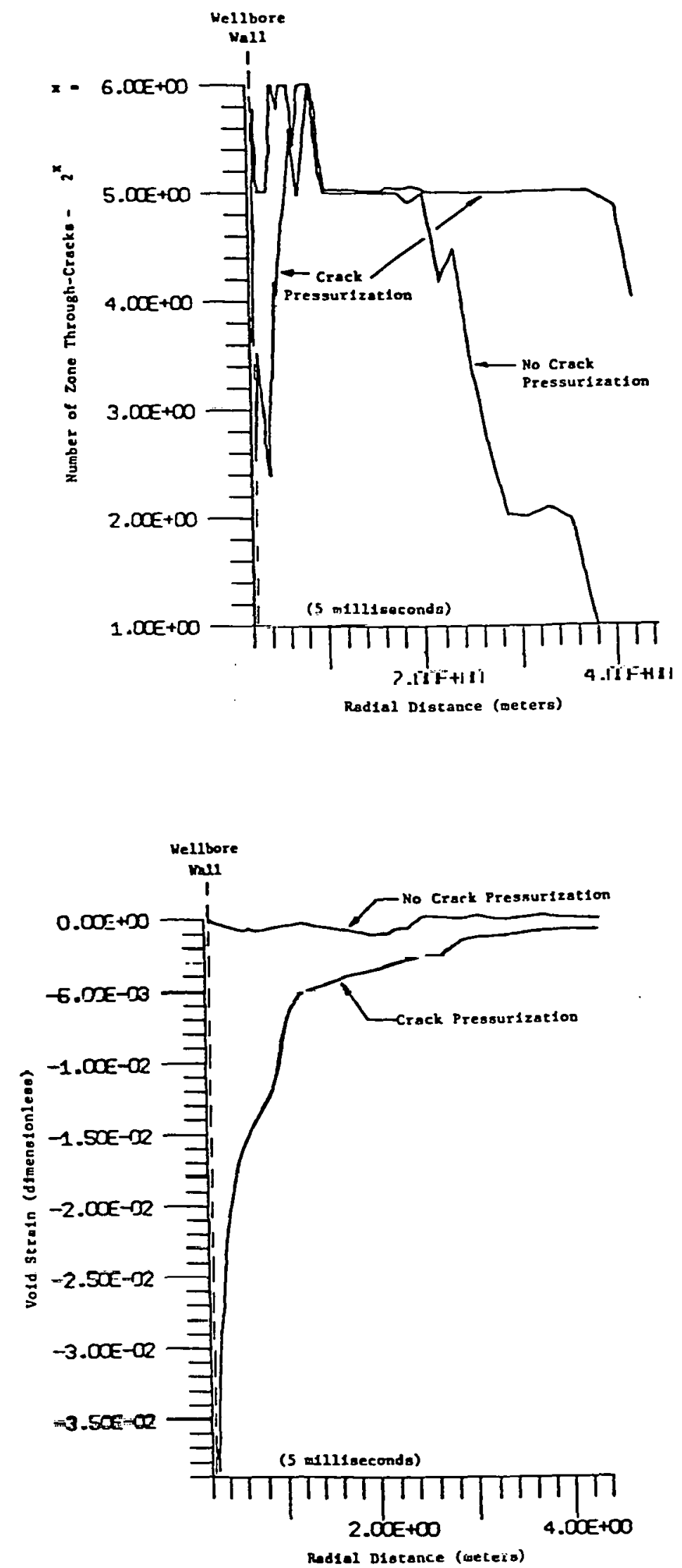

a) Number of Cracks vs. Radial Distance, Crack Pressurization and No Crack Pressurization
b) Void Strain vs. Radial Diatance, Crack Pressurization and No Crack Pressurization

FIGURE 4. EL836 Stimulation of Gas Shale 
One important variant of the explosive stimulation techniques involves displacing a low-viscosity high-sensitive explosive into the formation prior to detonation. Displacement of an explosive into the formation allows for a greater quantity of explosive to be utilized in a stimulation treatment and supposedly provides a better stimulation as the explosive is detonated in the induced and natural fracture system in which it has been injected. The displaced explosive technique has been developed and field tested by several companies, most notably the Petroleum Technology Corporation (PTC), the Talley Frac Corporation, and the GOEX Corporation. The Talley and PTC techniques are only utilized in open holes where some residual quantity of explosive remains and is detonated. The GOEX process is designed to be utilized in a cased hole with a cement plug completely filling the wellbore in the vicinity of the displaced explosive so as to minimize damage to the casing. Although each of these three techniques, as well as several other comparable methods, have been tested in numerous wells, none of them is commercially accepted at present.

The PTC Astrofrac process has been tested in several Devonian shale wells over a period of six years (Schott and Nuckols, 1979; Beckelman and Spencer, 1979). While the PTC wells gave impressive initial open flows after stimulation, averaging $314 \mathrm{MCF}$, these high flows were not sustained, supposedly due to well cleanup problems. In addition, many of the wells stimulated by the PTC Astrofrac process experienced operational difficulties wherein the explosive detonated prematurely and prior to its complete displacement into a fracture system around the wellbore. Much of the enhanced production may have been caused by the effects of explosive detonation in a fully loaded wellbore. As noted by Schott and Nuckols, it is aiso possible that significant fracturing was developed by the explosive gases pressurizing the wellbore in a region between where the explosive was detonated and a containment tamp was placed. In addition to the unknown physical effects, the displaced explosive techniques have been hindered by many operational and technical difficulties. In order that the explosive might have a reasonable probability of detonating in the thin fractures into which it has been injected, the explosive formulation must be quite 
sensitive. This sensitivity requires that either extreme explosive handling precautions be taken on the surface or that the explosive formulation be mixed downhole (as in the PTC Astrofrac technique) with a concordant complication of the downhole engineering and hardware. Even careful surface procedures do not preclude the risk of premature detonation as occurred in an October 1980 test of the GOEX process on a Columbia Gas well in Trumbull County, Ohio. As has been documented by a series of tests at Sandia (Neel, et al., 1979) even the explosive formulations designed for detonation in fractures do not perform such that detonation can be assured. Any delays between the displacement of the explosive into the formation and its detonation could result in the partial reclosing of the explosive filled fractures with a concordant loss in detonability. The inability to assure detonation or even deflagration of the exprosive displaced into fractures is a serious detriment to the viability of the displaced explosive techniques.

Tailored-Pulse-Loading

Because of the inherent low permeability of Devonian gas shale, any stimulation technique applied to it must entail some in-formation fracturing. A principal objective of explosive techniques has been the formation of multiple fractures and/or extension of natural fractures by loading the rock dynamically. Tailored-pulse-loading represents a stimulation technique which has been proposed to optimize the fracture formation and growth. The desired result is to create cracks of adequate extent in preferred directions so as to fntersect as Illary gas bearing natural fractures as possible, without the wellbore damage typically associated with explosive borehole shooting. A detailed knowledge of the relationships between the processes controlling rock fracture and the dynamic stress history is a necessity in efforts to optimize the explosive stimulation pressure-time history. Much recent research has been directed towards an understanding of the stimulation phenomena and several stimulation processes have been developed to quantify and demonstrate the pulse tailored concept.

The optimized pulse would avoid 1 imitations inherent in both hydraulic fracturing and explosive fracturing. Hydraulic fractures, which are initiated and propagated at pressures that are slightly higher than the 
minimum in situ stress and for pumping times that are on the order of hundreds of seconds, typically produce only a single pair of fractures where orientation is aligned with the in situ stresses. Explosive detonations, which usually have peak pressures that are orders of magnitude above the in situ stresses and occur in microseconds, often cause considerable borehole crushing and leave a residual compressive stress zone around the wellbore. The wellbore damage and stress cage will often seal off any cracks that are formed further from the wellbore. A tailored-pulse would incorporate the benefits of hydraulic and explosive fracturing by imparting a controlled pressure load such that: 1 ) the peak radial stress is below the flow stress of the rock; 2) the peak hoop stress is above the tensile strength of the rock; 3) the initial loading rate is large enough to initiate multiple fractures; and 4) the duration of the pulse and the permanent gases generated by the explosive or propellant are sufficient to extend the multiple fractures for relatively long distances.

In support of the continued evaluation of the tailored-pulse-loading concept an analysis of three tailored-pulse-loading parameters has been undertaken by SAI to access their importance in gas well stimulation. A numerical evaluation (Barbour and Mihalik, 1980) was performed using the STEALTH/CAVS codes and was intended to provide a measure of the effects of various tailoredpulse load configurations on fracture development in Devonian gas shale. The three parameters considered in the sensitivity analysis were; 1) loading rate, 2) decay rate, and 3) sustained peak pressures. The range of amplitudes and rates of the applied wellibore pressure-time histories typify intermediate loading conditions common for propellant stimulation treatments.

By varying these three parameters in six computations and comparing the relative differences in fracture initiation and propagation, the importance of each can be determined. It should be noted that this sensitivity analysis did not include the influence of gas penetration and pressurization of the induced cracks. The effect of internal crack pressurization on fracture growth is extremely important and, as discussed later, may override some of the sensitivities noted here. Results for the sensitivity analysis without crack pressurization suggest the following: 
1) The number of fractures initiated is directly related to the loading rate applied to the wellbore wall. For a pulse loading rate of $10 \mathrm{GPa} / \mathrm{sec}$ a single crack initiated and propagated from a 0.1 meter radius wellbore in shale to approximately 0.3 meter. For a pulse loading rate of $100 \mathrm{GPa} / \mathrm{sec}$ four equal length cracks developed to approximately 0.3 meter. For a pulse loading rate of $1000 \mathrm{GPa} / \mathrm{sec}$ eight cracks developed, four to a distance of approximately 0.3 meter and four to a distance of approximately 0.03 meter.

2) If yielding of the rock can be prevented or minimized, by malntaining low peak pressures in the wellborc, increasing the pulse loading rate, to say $10,00 \mathrm{GPa} / \mathrm{sec}$ or more, should initiate additional multiple fractures.

3) Fracture initiation does not appear to be related to the tailored-pulse decay rate. Fracture extension may be influenced by the rate of decay. The slower the decay rate, the longer the crack extension.

4) Fracture initiation does not appear to be improved by a high pressure plateau in the tailored-pulse. Fracture propagation may be enhanced if the maintained wellbore pressure plateau is high enough to extend the range of the tangential tensile stresses to greater radial distances.

In light of these conclusions, optimization of a wellbore tailored-pulse load should give consideration to maximizing the loading rate of the applicd pulse in order to maximize multiple crack initiation. Fajler loading rates generally are associated with larger peak borehole pressures because of the nature of explosive/propellant energy release. To achieve the desired multiple crack initiation without the detrimental effect of rock yielding, the pulse should have a fast rate of loading but with low peak amplitude. 
The influence of internal crack pressurization on fracture growth, due to penetrating fluid reaction products from the wellbore, is of paramount importance in the tailored-pulse-loading concept of wellbore stimulation. Pulse histories in the wellbore may be defined, based on the results of the parameter sensitivity analysis described above, to optimize multiple fracture initiation and minimize yielding at the wellbore wall. The extension of initiated cracks, however, requires a mechanism other than the induced stress waves to continue the fracture propagation. With very high-rate loading conditions, such as would occur in the detonation of a tigh energy explosive, the induced tangential tensile stresses are the primary crack propagating mechanism. At lesser loading rates, such as would occur in the deflagration of a propellant, the induced tangential tensile stresses are of lesser magnitude and shorter duration. Thus, to continue crack growth, internal pressurization of the cracks is necessary. Figure 5 shows the influence of crack internal pressurization on crack growth (Barbour, 1980). Figure 5a is without crack pressurization and Figure $5 b$ is with crack pressurization.

Initial efforts on tailoring the borehole pressure pulse were carried out by Physics International and have resulted in the Dynafrac process (Moore, et al., 1977). Subsequent efforts have been performed by Sandia Laboratories (Gas-Frac; Warpinski, et al., 1979) and Kinetech Corporation (Kinefrac; Fitzgerald and Anderson, 1978). Dynafrac uses a short rise time explosive pulse to initiate multiple fractures with a superimposed slow burn-rate propellant pulse (as the explosive pulse decays) to extend the fracturcs. A water buffering flutd is employed to provide the desired loading rate while restricting peak pressures to below those which cause well bore damage. Water is forced into the induced fractures to assist in their extension. Kinefrac and Gas-Frac use propellant charges with loading rates slower than explosives but large enough to initiate multiple fractures. Both are high gas generators with low enough peak amplitudes to minimize borehole crushing and stress cage development. Abundant gas generation maintains the pulse long enough to permit the high pressure gases in the borehole to enter and extend the created multiple fractures. A water decoupling fluid is employed in the Kinefrac process, the water being forced into the fractures by the expanding gases. 


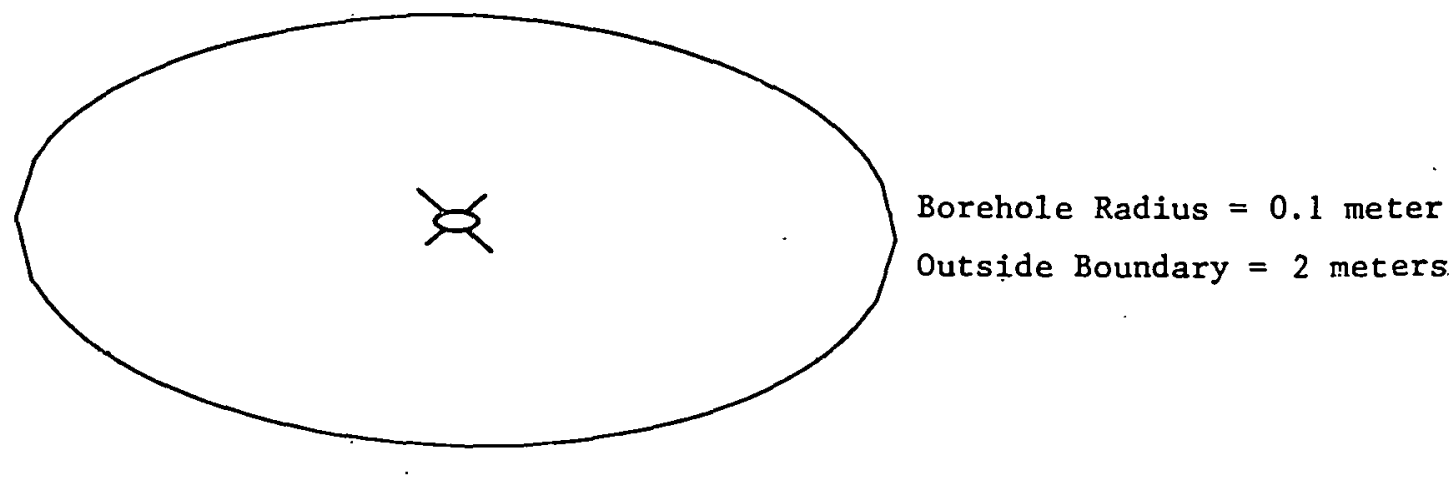

a) without crack internal pressurization (calculation time $=10$ m1lliseconds)

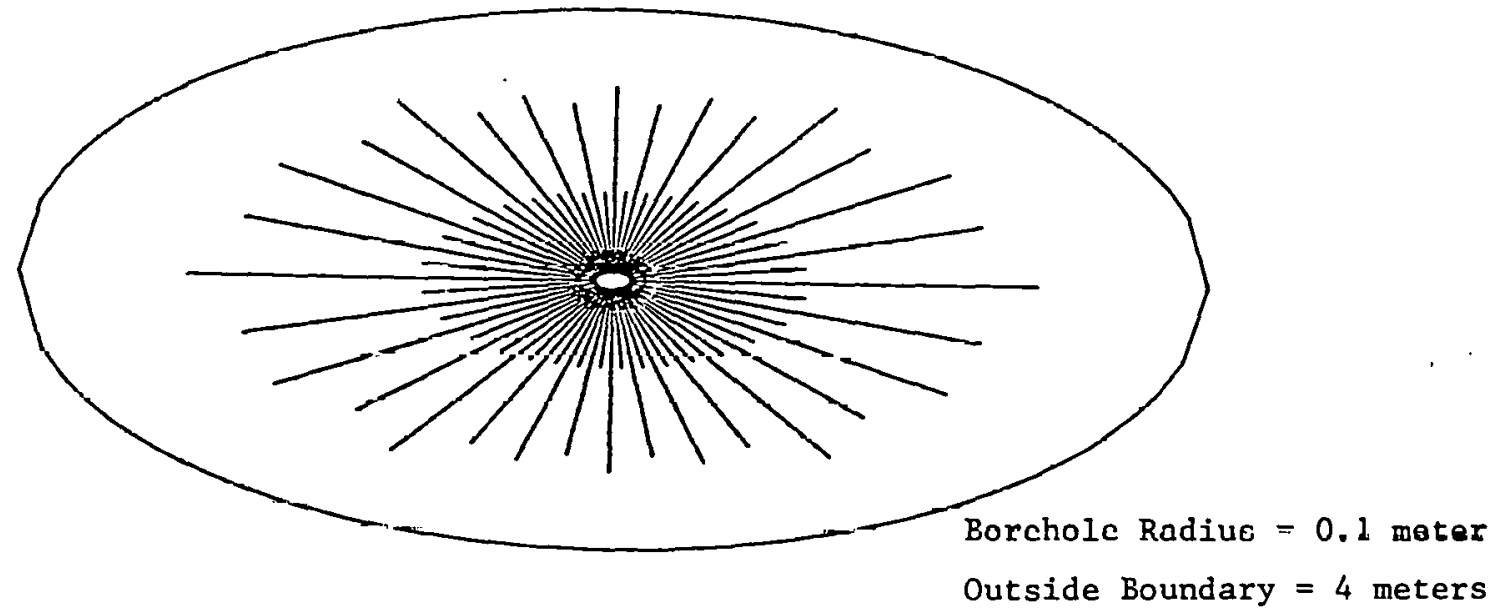

b) with crack internal pressurization (calculation time $=10$ milliseconds)

Pulse loading rate $=100 \mathrm{GPa} / \mathrm{sec}$.

FIGURE 5. Tailored-Pulse-Loading Stimulation of Gas Shale 
The Multi-Frac Test Series (Schmidt, et al., 1980) recently conducted at the Nevada Test Site (NTS) had two purposes: (1) evaluate and compare five tailored-pulse-loading stimulation treatments under in situ conditions to determine the ability of each to produce multiple fractures and to enhance formation permeability and (2) provide data for testing and verification of various numerical modeling schemes presently being developed to describe the complex behavior of dynamic wellbore stimulation in a deep wellbore.

Five full-scale shots were performed in a thick ash-fall tuff formation. Conducted in horizontal boreholes drilled from a tunnel under 430 meters of overburden, the test site provided both realistic in situ conditions and access to the test zone by mineback permitting direct observation of the test results. Data for model verification were collected during each test using stress gages and accelerometers embedded in instrumentation holes in the surrounding rock. Each test monitored the cavity pressure using transducers in each borehole. Pre-test and post-test evaluation included TV and caliper logs and permeability measurements. Laboratory experiments were performed on the core obtained from the boreholes to determine the static and dynamic material properties. The combination of the site specific material data, actual cavity pressure, rock stress and acceleration data and direct observation of the induced fractures provided the necessary information required to numerically model each test. The five tailored-pulse-loading concepts tested involved:

(A) a small-diameter explosive decoupled with a water pad, (unaugmented Dynafrac)

(B) a small-diameter decoupled explosive with water pad and an added propellant booster, (augmented Dynafrac)

(C) a small-diameter propellant charge with a pressurized water pad, (single Kinefrac shot)

(D) three successive shots of case $c$, (multiple Kinefrac shots), and

(E) a full-diameter charge of progressively burning propellant (Gas-Frac). 
The Multi-Frac Test Series has shown that multiple fractures can be created from a borehole while avoiding the wellbore damage and stress cage formation by using appropriately designed tailored-pulse techniques. The Gas-Frac experiment produced a highly fractured zone immediately around the wellbore (to about 2 meters) with one predominant fracture extending to about 8 meters. The augmented Dynafrac experiment (in which the explosive failed to detonate), and the single and multiple Kinefrac experiments resulted in modest stimulation with radial fractures extending to less than a meter from the wellbore. The unaugmented Dynafrac experiment enlarged and distorted the borehole with no fracture development. Table 2 is a summary of the test results obtained prior to mineback.

The results of these tests and previous experiments (Warpinski, et al., 1979) at the NTS suggest that a multiple fracture criterion be based on borehole pressure loading rate. Peak pressure conditions may not be important if the loading-rate requirements are adequate. Post-test evaluation of the numerical models that are currently being used to describe the effects of dynamic wellbore stimulation is currently in progress.

SRI Interialiund and SAI are currently involved in numerical simulations (using finite-difference calculational techniques) of the above mentioned processes to cooperatively evaluate the stimulation treatments on the fracture developement that their fracture models compute. The SRI International NAG-FRAG fracture model (Shockey, et al., 1976) uses a tensile stressdependent criterion for microflaw activation and coalescence to describe crack development. The influence of various hypothetical pulse-tailored pressure profiles, in numerical borehole models, has been shown to have a significant influence on the computed fracture distribution (McHugh, et al., 1980). SAI's CAVS fracture model uses a tensile stress criterion to define fracture initiation and propagation and describes the compatibility of the stress tensor adjustments as cracks open and close in three orthogonal directions (Maxwell, 1979). The influence of the rock's yielding properties and of crack propping and internal pressurization have been described (Barbour, et al., 1980 a). The effects of anisotropic in situ stress field and existence of preexisting fractures is currently being investigated by SAI. The University of Maryland (Fourney and Barker, 1979), (Fourney, et al., 1980), and SRI International (McHugh, 1930) are currently involved 
TABLE 2

PERMEABILITY ENHANCEMENT

(From Schmidt, et al. 1980)

\begin{tabular}{|c|c|c|c|c|c|}
\hline CASE & TAILORED-PLLSE CONCEPT & $\begin{array}{l}\text { PRE-TEST } \\
\text { PERMEAB ILITY } \\
\text { (md) }\end{array}$ & $\begin{array}{l}\text { POST-TEST } \\
\text { PERMEABILITY } \\
\text { (md) }\end{array}$ & $\begin{array}{l}\text { FACTOR OF } \\
\text { INCREASE }\end{array}$ & $\begin{array}{l}\text { OBSERVATIONS } \\
\text { FROM TV LOG }\end{array}$ \\
\hline A & $\begin{array}{l}\text { DECOUPLED EXPLOSIVE } \\
\text { WITH WATER ?AD }\end{array}$ & 0.20 & 0.05 & 0.25 & $\begin{array}{l}\text { ENLARGED, DIS- } \\
\text { TORTED BOREHOLE }\end{array}$ \\
\hline B & $\begin{array}{l}\text { DECOUPLED EXPLOSIVE" } \\
\text { WITH PROPELLANT PUSHER } \\
\text { (WATER PAD) }\end{array}$ & 0.83 & 5.6 & 7 & $\begin{array}{l}\text { NO FRACTURES } \\
\text { APPARENT }\end{array}$ \\
\hline C & $\begin{array}{l}\text { SMALL DIAMETER PROPELLANT } \\
\text { WITH PRESSUFIIZED WATER PAD }\end{array}$ & 0.0015 & $0.008^{\star *}$ & $5^{* *}$ & $\begin{array}{l}\text { MULTIPLE FRACTURES } \\
\text { (VERY NARROW) }\end{array}$ \\
\hline D & $\begin{array}{l}\text { THREE SHOTS OF CASE C WITH } \\
\text { PRESSURIZED WATER PAD }\end{array}$ & 0.007 & 0.034 & 5 & $\begin{array}{l}\text { MULTIPLE FRACTURES } \\
\text { (NARROW) }\end{array}$ \\
\hline$E$ & $\begin{array}{l}\text { FULL BORE, PROGRESSIVELY- } \\
\text { BURNING PROPELLANT WITH } \\
\text { AIR PAD }\end{array}$ & 0.014 & 25.0 & 1800 & $\begin{array}{l}\text { MULTIPLE FRACTURES } \\
\text { (WIDE) }\end{array}$ \\
\hline
\end{tabular}

- explosive did nOt detonate

- SOME PERMEABILITY INCREASE MAY bE DUE tO FRACTURE CAUSED bY EXPERIMENT E 
in laboratory experimental programs to establish the influence of tailoredpulse loading on the fracture development in borehole models in polymers and rock. Currently under investigation are the influences of anisotropic stress fields and crack pressurization.

Results of one-dimensional cylindrical geometry numerical calculations using SAI's CAVS tensile failure model have been used (Barbour, et al., 1980 a) to evaluate the sensitivity of fracture development around an explosively loaded wellbore upon 1) rock mass properties and 2) crack propping. The nature of the stimulating pressure profile and fracture pressure profile as related to the rock yielding properties can significantly modify the fracture pattern around a borehole. The rock yielding causes stress redistributions which can severely 1 imit fracture yruwth. Figure $G$ shows the effect of tivo yield surfaces for a numerical model of ash-fall tuff subjected to the unaugmented Dynafrac process. The lower yield strength models illustrate the detrimental effect of wellbore yielding and stress redistribution, with the length of fractures into the formation being severely reduced. Without a propping mechanism to hold cracks open, once they are created, explosively induced fractures could have such luw curiductivities as to serfously limit production potential. The once opened cracks will reclose in response to compressive hoop stresses that redevelop after the hoop tensile stress wave passes. A "skip-zone" of reclosed cracks often developes as shown in Figure 7. 


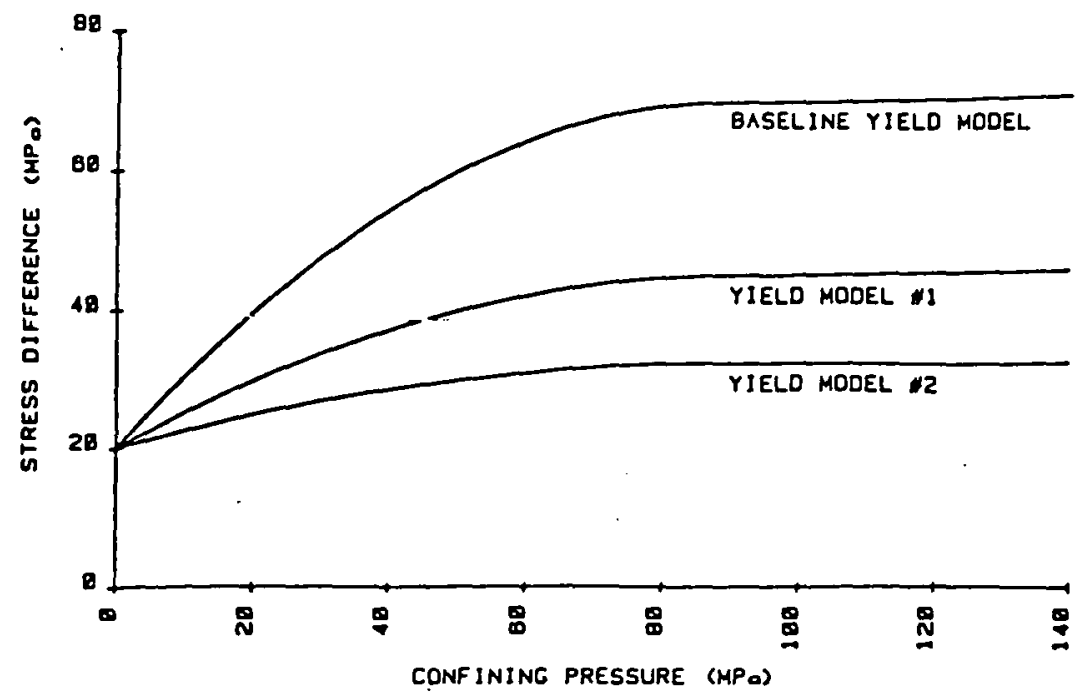

ASH-FALL TUFF' YIELD MODELS

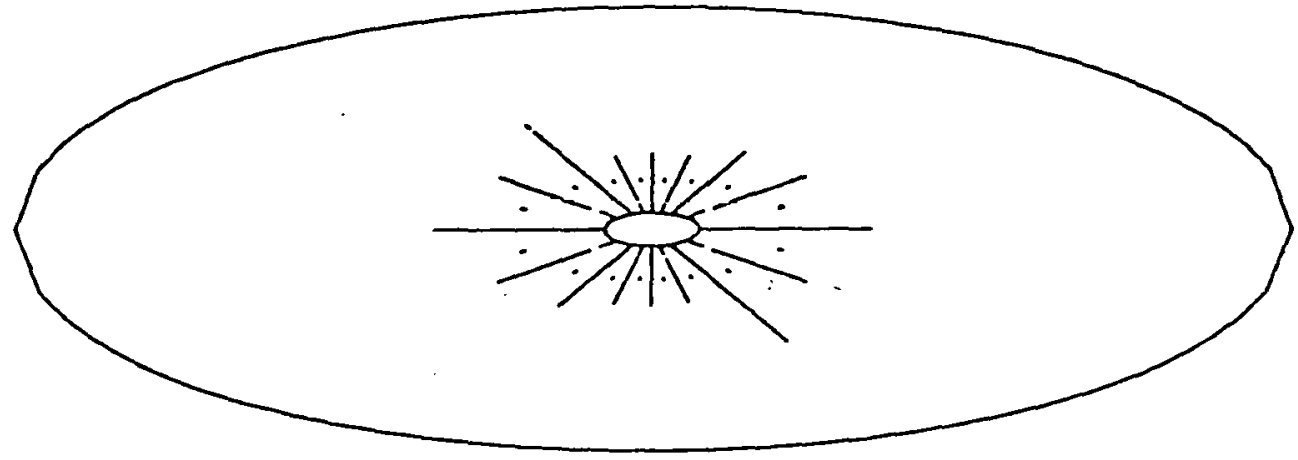

BASELINE YIELD

Outside Boundary $=100 \mathrm{~cm}$

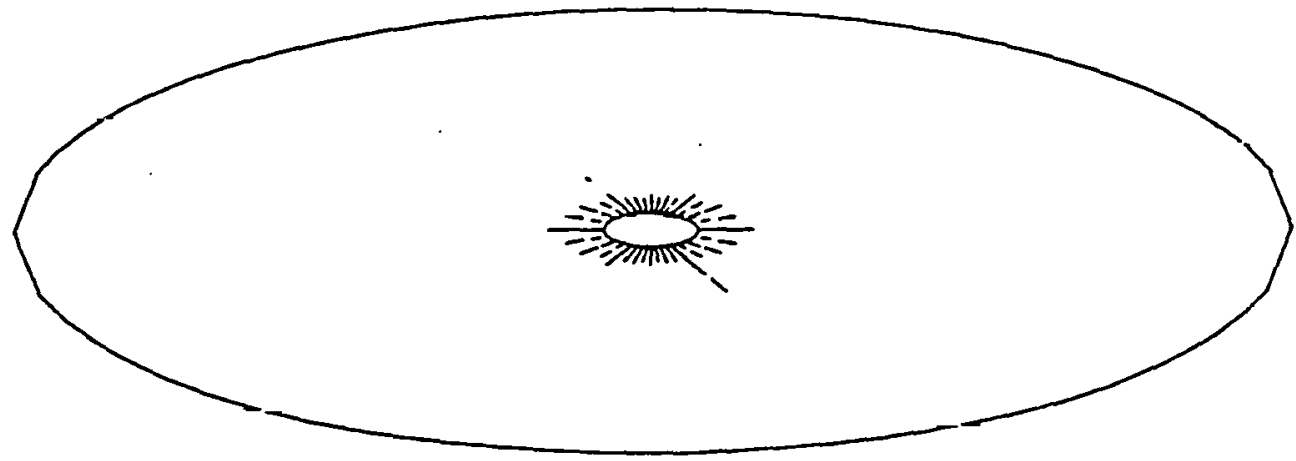

YIELD 2

Outside Boundary $=100 \mathrm{~cm}$

FIGUPE 6. Effect of Rock Yielding on Fracture Development 


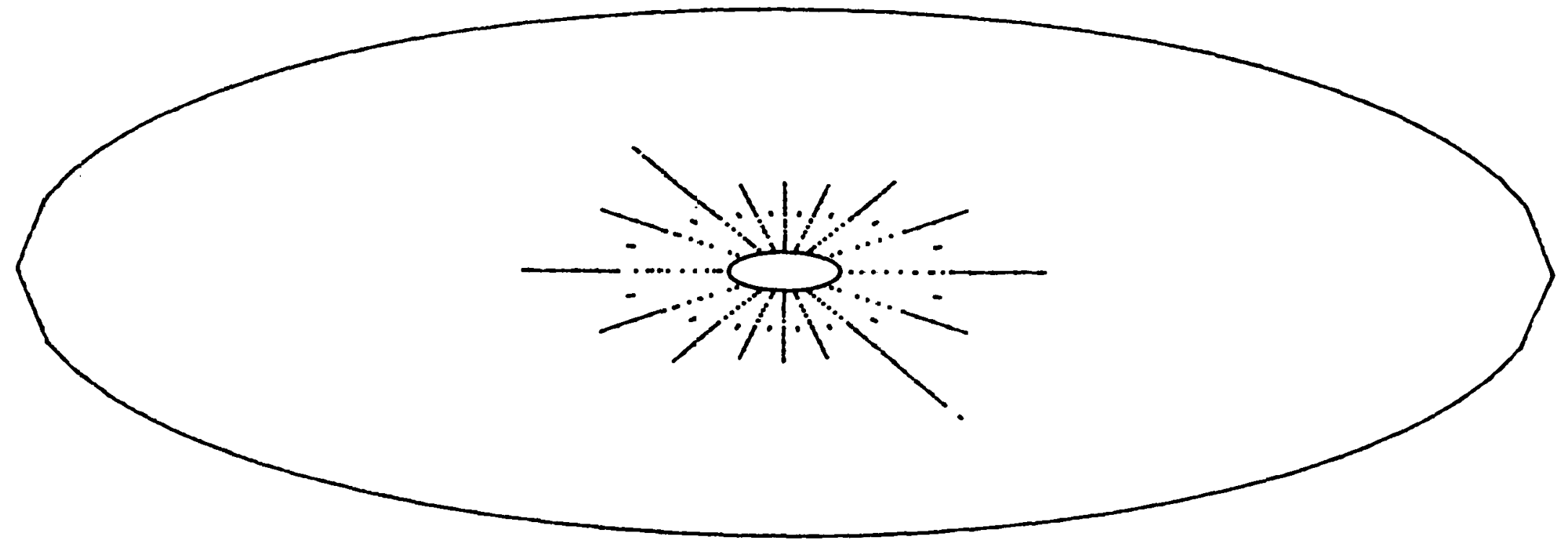
FFACTURE PLOT WITHOUT CRACK PROPPING
(Dotted Portion Represents Closed Cracks)
Outside Boundary $=100 \mathrm{~cm}$


There is not yet a sufficient data base on either Devonian shale production characteristics or the effects of explosive and hydraulic stimulation treatments upon which to base a quantitative stimulation rationale for shale wells (Komar, 1978). There is adequate data, however, to support observations on the potential merits of the various explosive and hydraulic stimulation treatments and to predict which types of treatments are apt to be most effective under certain production conditions. Most importantly, the increased understanding of shale production characteristics and stimulation treatment effects being gained in the EGSP and reviewed in this study provides a foundation for defining the additional research and field testing efforts required to develop a firmly based stimulation rationale for shale wells.

All of the studies on Devonian shale production characteristics conducted to date agree and confirm that shale well production is fundamentally controlled by the in situ natural fracture system. While some of these studies (Kuuskraa, et a1., 1978; Ford, 1979) conclude that the integrated effect of the in situ fracture system is to give shale wells conventional "blanket sand" production characteristics; more recent studies (Smith, et a1., 1979; McCarthy, et a1., 1979; Sawyer and Alam, 1980) argue that naturally fractured shale reservoirs do not display conventional production characteristics. Certainly, the many fold increases in production observed with conventional wellbore shooting and small scale hydraulic stimulation treatments attest to the heterogeneous characteristics of shale production on the scale of initially drilled wellbore diameters and even on the scale of the effective radii of stimulation treatments.

As shale well production is dominated by the in situ natural fracture system, it is imperative that significant efforts be made to quantitatively describe the in situ fracture system and its control upon shale weil production. As the benefits of various explosive and hydraulic stimulation treatments clearly depend upon the interaction between the induced wellbore fractures and the pre-existing natural fractures, it is equally imperative that increased efforts be devoted to quantitatively understanding the effects of the stimulation treatments. Only by fully integrating fractured reservoir production characteristics with the effects 
of explosive and hydraulic treatments can a quantitative and supportable stimulation rationale be developed.

Although the data base and the integrating physical models are not yet adequate, it is possible to make specific recommendations on the applicability of various stimulation treatments to shale wells. 'The experience and data on both hydraulically and explosively stimulated wells suggest that formation damage and usually related cleanup problems are a major concern.

For the hydraulic type treatments the use of low-residual-fluid treatments is highly recommended. The lower the initial formation or reservoir pressure, the more strongly the low-residual-fluid treatments may be recommended. The excellent shale well production which is frequently observed with only moderate wellbore enlargement treatments suggests that attempts to extend fractures to greater distances with massive (or even large-scale) hydraulic treatments may not be warranted. Immediate research efforts should be concentrated upon limiting production damage by fracturing fluids retained in the formation, and upon improving proppant transport and placement so as to maximize fracture conductivity. Additional information on the morphology of induced fractures in naturally fractured formations is essential to evaluating the merits of large-scale and pure $\mathrm{N}_{2}$ treatments.

The occasionaliy spectacular production increases resulting from both conventional and displaced explosive treatments suggest that the modest wellbore enlargement resulting from such treatments may provide a viable and cost effective approach to shale well stimulation. In that some, if not a11, of the benefits obtained with displaced explosive treatments may be attributed to simple wellbore fracturing, future efforts should be concentrated upon improving wellbore fracturing while minimizing consequent damage rather than upon the displaced explosive technique per se. The recurring operational problems with the displaced explosive technique further dictate that this approach is unattractive.

In selecting an explosive treatment for application to a shale well, consideration should be given to minimizing mechanical damage to the formation and to selecting an explosive formulation with minimal water generation characteristics. If the well is to be cleaned out following 
an explosive treatment, it is imperative that this cleanout be done without the aid of water or even a water-based foam. Immediate research efforts should be concentrated upon the mechanisms by which wellbore fractures are induced and propagated, especially in naturally fractured formations, and upon techniques for minimizing mechanical formation damage by explosive/propellant treatments. The data available to date strongly supports additional research efforts on the tailored-pulseloading concept. 


\section{REFERENCES}

Barbour, T.G., "Evaluation of EL836 Explosive Stimulation of Devonian Gas Shale," Task Technical Report Under Contract DE-AM21-78MC08216 for METC. Prepared by Science Applications, Inc., Fort Collins, Colorado, September 1980.

Barbour, T.G., and Mihalik, G.R., "Parameter Sensitivity Analysis of Tailored-Pulse-Loading Stimulation of Devonian Gas Shale," Task Technical Report under Contract DE-ANi21-78MC08216 for METC. Prepared by Science Applications, Inc., Golden, Colorado, November 1980.

Barbour, T.G., Maxwel1, D.E., and Young, C., "Numerical Model Development for Stimulation Technologies in the Eastern Gas Shales Project," Task Technical Report under Contract EY-78-C-21-8216 for METC, Science Applications, Inc., Fort Collins, Colorado, January 1980 a.

Barbour, T.G., Blanton, T.L., and Young, C., "Computational Analysis of Dynamic Micro-Stimulation Treatments for Offset-Well Test Program,"

Task Technical Report under Contract DE-AM21-18MCO8216 for METC.

Prepared by Science Applications, Inc., Golden, Colorado, October 1980 b.

Beckelman, B.F., and Spencer, A.N., "Summary of Results from Department of Energy Contracts 685, 686, and 687 - July 1, 1976 through June 30, 1979" ROCKCOR Presentation, July 30, 1979.

Blanton, T.L., "Comparison of Micro-Stimulation Treatments Available for Use in Offset Well Test Program," Interim Technical Report Under Contract DE-AM21-78MC08216 for METC. Prepared by Science Applications, Inc., Steamboat Springs, Colorado, 1980.

Blaurer, R.E., "Foam Fracturing Shows Success in Gas, 0 il Formations," 011 and Gas J., Auyust 4, 1975, pr. 57-60.

Coursen, D.L., personal communication, December 1980.

Cremean, S.P., Mcketta, S.F., Owens, G.L., and Smith, E.C., "Massive Hydraulic Fracturing Experiments of the Devonian Shale," Columbia Gás System Service Corporation, Vols. I and II, (1979).

Evans, K.F., Holzhausen, G.R., and Wood, M.D., "The Mapping of Nitrogen Gas Induced Hydraulic Fracture in Devonian Shale by Observation of the Associated Surface Deformation," SPE paper no. 8933, presented at Unconventional Gas Recovery Symposium, 1980.

Fitzgerald, R. and Anderson, R., "Kine-Frac: A New Approach to Well Stimulation," ASME Paper 78-PET-25, ASME Energy Technology Conference and Exhibition, Houston, Texas, November 1978. 
Ford, W.K., "The Characterization of the Production Mechanism in the Devonian Shale and its Sensitivity to Changes in Various Reservoir Parameters," Proc. 3rd Eastern Gas Shales Symposium, METC/SP-79/6, Morgantown, West Virginia, October 1979.

Fourney, W.L. and Barker, D.B., "Characteristics of a Crack Oriven by Explosive Loading," Prepared for DOE/METC by University of Maryland Photomechanics Laboratory of Mechanical Engineering Department, College Park, Maryland, August 1979.

Fourney, W.L., Holloway, D.C., and Barker, D.B., "Pressure Decay in Propagating Cracks" (for information only - unofficial). Prepared for DOE/METC by University of Maryland, Photomechanics Laboratory of Mechanical Engineering Department, College Park, Maryland, January 1980.

Hofmann, R., "STEALTH, A Lagrange Explicit Finite-Difference Code for Solids, Structural and Thermohydraulic Analys is," EPRI NP-176-1, Electric Power Research Institute, Palo Alto; California, April 1978.

Komar, C.A., "Development of a Rationale for Stimulation Design in the Devonian Shale," SPE Paper 7166, Omaha, Nebraska, 1978.

Komar, C.A., Yost, A.B., and Sinclair, A.R., "Practical Aspects of Foam Fracturing in Devonian Shale," SPE Paper 8345, Las Vegas, Nevada, September 1979.

Kuuskraa, V.A., Brashear, J.P., Doscher, T.M., and Elkins, L.E., "Enhanced Recovery of Unconventional Gas Sources," Section of Devonian Shale Gas of the Appalachian Basin, Vol. III, pp. 1-79, (1978).

Liebenthal, A. M., Komar, C., Rieke, H.H., and Skillern, C.R., "Economic Analysis of Foam Fracturing in the Devonian Shales: Preliminary Report," SPE Paper 8738, 1979.

Loving, F.A., and Simmons, W.F., "Study of Explosive Stimulation in Devonian Shale Gas Wells," Final Report under Contract DE-AC21-79 MC11843 for METC. Prepared by E.I. duPont de Nemours and Co., Martinsburg, West Virginia, November 1980.

Maxwe11, D.E., "The CAVS Tensile Failure Model," Internal Report SATR 79-4, Science Applications, Inc., San Leandro, California, April 1979.

McCarthy, H.E., "An Engineering and Economic Evaluation of Devonian Shale Production Techniques, "Briefing to METC, Lakeview Inn, Morgantown, West Virginia, August 1979.

McHugh, S.L., Murri, W.J., Seaman, L., Curran, D.C., and Keough, D.C., "Fracture of Devonian Shale by Tailored Pulse-Loading," SRI International Final Report to DOE/METC under Contract EY-76C-03-0115-127, Menlo Park, Cal ifornia, December 1978. 
McHugh, S.L., Curran, D.R. and Seaman, L., "The NAG-FRAG Computational Fracture Model and Its Use for Simulating Fragmentation and Fracture," SESA Fall Meeting, Soc. Exp. Stress Anal., Fr. Lauderdale, Florida, October 1980.

Moore, E.T., Mumma, D.H., and Seifert, K.D., "Dynafrac - Application of a Novel Rock Fracturing Method to 0il and Gas Recovery," Physics International Report 827, San Leandro, California, April 1977.

Neel, R.R., Jacobson, R.D., and Ray, C.W., "An Evaluation of Four Slurry Explosives Proposed for Use in Explosive Fracturing of $0 i 1$ Shale Formations," Sandia Laboratories Report, SAND-78-1002, Albuquerque, New Mexico, June 1978.

Sawyer, W.K., and Alam, J., "Pressure Transient Testing in Unconventional Gas Reservoirs," SPE-9397, SPE 55th Annual Technical Conf. and Exhib., Dallas, Texas, Septemiler 1980.

Schmidt, R.A., Warpinski, N.R., and Northrup, D.A., "In Situ Testing of Well Shooting Concepts," Proc. 3rd Eastern Gas Shales Symposium, METC/SP-79/6, Morgantown, West Virginia, October 1979.

Schmidt, R.A., Warpinski, N.R., and Cooper, P.W., "In Situ Evaluation of Several Tailored-Pulse Well-Shooting Concepts," Unconventional Gas Recovery Symposium, SPE-8934, Pittsburgh, Pennsylvania, May 1980.

Schott, G.L. and Nuckols, E.B., "Technical and Engineering Evaluation of Astrofrac," Report to Enhanced Gas Recovery Program, METC, Los Alamos Scientific Laboratory.

Shockey, D.A., Curran, D.R., Austin, M., and Seaman, L., "Development of a Capability for Predicting Cratering and Fragmentation Behavior of Rock," SRI International Final Report to Defense Nuclear Agency, DNA 3730F, Menlo Park, Californiá, May 1976.

Smith, E.C., Cremean, S.P., and Kozair, G., "Gas Occurrence in the Devonian Shales," Presented at the 3rd Eastern Gas Shales Symposium, METC/SP-79/6. Morgantown, West Virginia, October 1979.

Warpinski, N.R., Schmidt, R.A., Cooper, P.W., Walling, H.C., and Northrup, D.A., "High-Energy Gas Frạ:: Multiple Fracturing in a Wellbore," Proc. 20th U.S. Symposium Rock Mech., Austin, Texas, pp. 143-152, June 1979.

Yost, A.B. II, "Effertiveness of Hydraulic Fracturing Treatments in the Devonian Shale," Proc. Ky. Oil and Gas Assn., 19/8.

Young, C. and Barbour, T.G., "Importance and Control of Hydraulic Fracture Containment in Shale Well Stimulation," Task Report, Science Applications, Inc., Fort Collins, Colorado, May 1979, 19 pp.

Young, C., "Rationale for Shale Well Stimulation," Proc. 2nd Eastern Gas Shales Symposium, METC/SP-78/-, Volume I, Morgantown, West Virginia, October, 1978. 